Rhode Island College

Digital Commons @ RIC

$1-1-2011$

\title{
Planned Cesarean Delivery and Urinary Retention Associated With Spinal Morphine
}

Susan M. DiBlasi

Rhode Island College

Follow this and additional works at: https://digitalcommons.ric.edu/etd

Part of the Geriatric Nursing Commons

\section{Recommended Citation}

DiBlasi, Susan M., "Planned Cesarean Delivery and Urinary Retention Associated With Spinal Morphine" (2011). Master's Theses, Dissertations, Graduate Research and Major Papers Overview. 205.

https://digitalcommons.ric.edu/etd/205

This Major Paper is brought to you for free and open access by the Master's Theses, Dissertations, Graduate Research and Major Papers at Digital Commons @ RIC. It has been accepted for inclusion in Master's Theses, Dissertations, Graduate Research and Major Papers Overview by an authorized administrator of Digital Commons @ RIC. For more information, please contact digitalcommons@ric.edu. 


\section{CESAREAN DELIVERY AND URINARY RETENTION}

\section{ASSOCIATED WITH SPINAL MORPHINE}

A Major Paper Presented

By

Susan M. DiBlasi

Approved:

Committee Chairperson

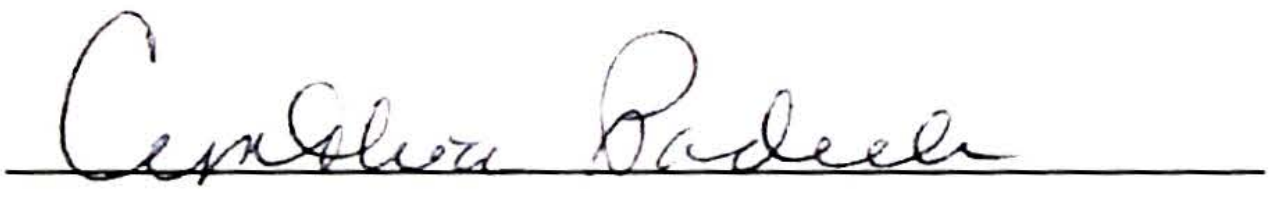

$5 / 15 / 11$

(Date)

Committee Members

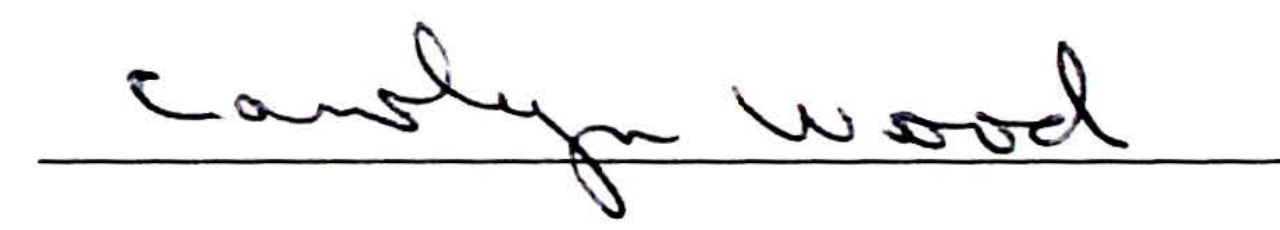

. 01.3111

(Date)

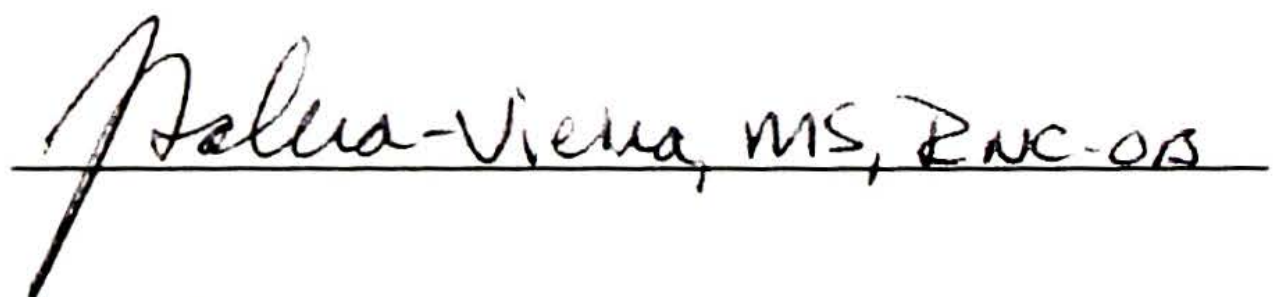

$5 / 9 / 11$

(Date)

Director of Master's Program

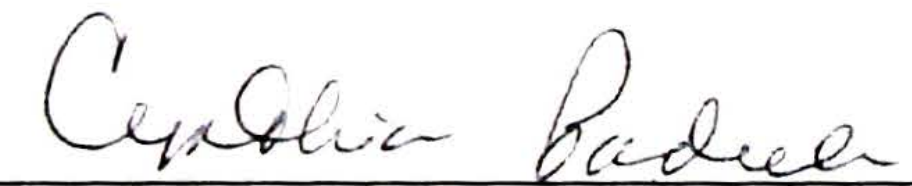

$5 / 15 / 1 i$

(Date)

Dean, School of Nursing

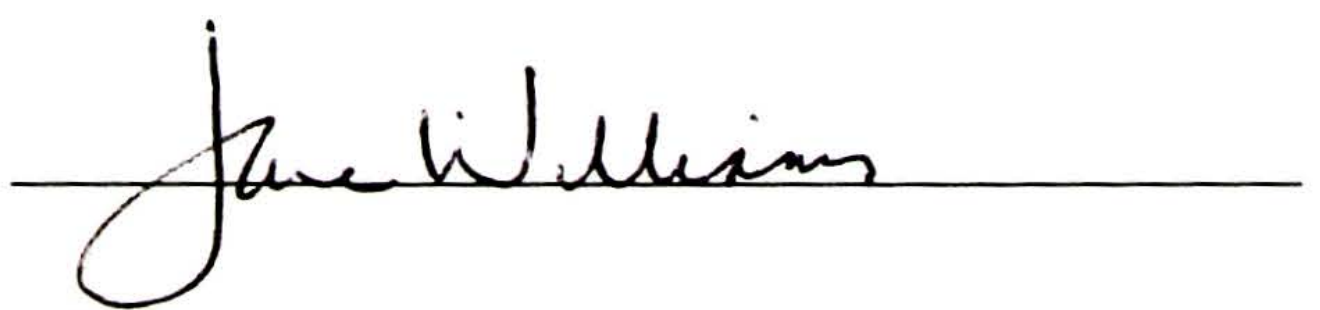

(Date) 


\section{CESAREAN DELIVERY \\ AND URINARY RETENTION \\ ASSOCIATED WITH SPINAL MORPHINE}

by

Susan M. DiBlasi

A Major Paper Submitted in Partial Fulfillment

of the Requirements for the Degree of

Master of Science in Nursing

in

The School of Nursing

Rhode Island College

2011 


\begin{abstract}
Cesarean delivery (CD) is the second most commonly performed surgery in the US, occurring in $31.8 \%$ of all births, totaling $1,372,843$ in 2007 . Nurses' feedback related to perceived increased urinary retention following use of spinal morphine for postoperative pain relief in elective CD's prompted a review of the literature. Limited research had been conducted in this area. The purpose of this study was to compare the occurrence of post elective CD urinary retention and dose of spinal morphine. A retrospective, quasi-experimental three group design, examined the relationship between urinary retention post elective CD and spinal morphine dose: 100,150 or $200 \mathrm{mcg}$. Records of one hundred and fifty patients, ages 17 to 39 , undergoing elective primary or repeat CD were examined. No statistically significant differences were found between the three groups. Implications for practice include continued use of spinal morphine in the aforementioned strengths as it provides superior pain relief with minimal side effects, and further evaluation of the incidence of urinary retention in $\mathrm{CD}$ patients receiving spinal morphine.
\end{abstract}

Keywords: Cesarean delivery, urinary retention, spinal anesthesia, morphine. 


\section{Acknowledgements}

The researcher acknowledges and appreciates the assistance of:

Cynthia Padula PhD RN, $1^{\text {st }}$ reader, advisor $\&$ mentor

Carolyn Wood PhD RN, $2^{\text {nd }}$ reader

Jean Salera-Vieira RN MSN, $3^{\text {rd }}$ reader

Kue Choi M.D.

Stephen Chesley, graphics

Nancy Ross MLS, reference acquisition

Kelly Taylor RN, IRB

Filomena Ferris and Carrie Hebert, retrieval of medical records

Most importantly my family: Paul, Kayla and Chelsea. "The wind beneath my wings".

Financial support was not provided. 


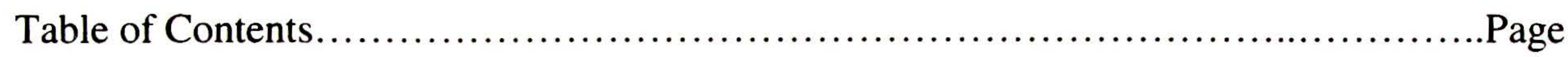

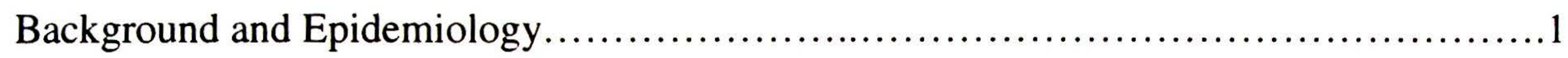

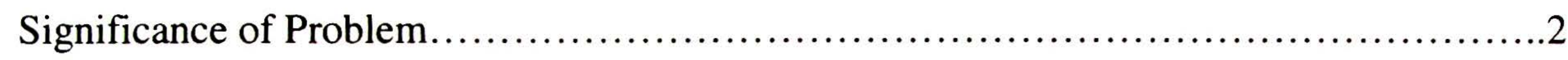

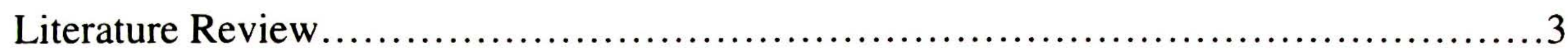

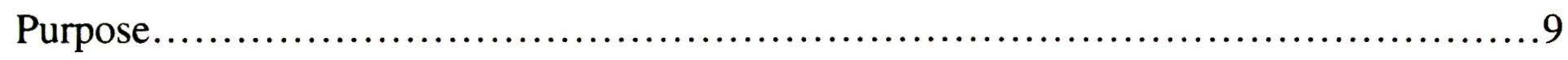

Framework and Conceptual Model............................................... 9

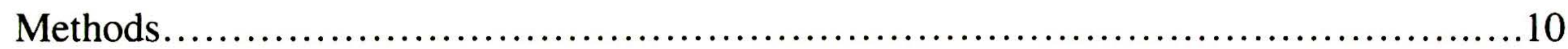

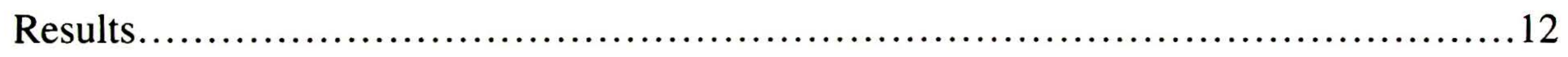

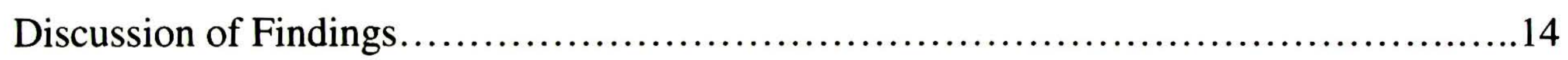

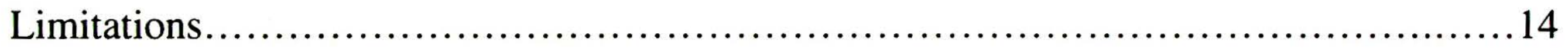

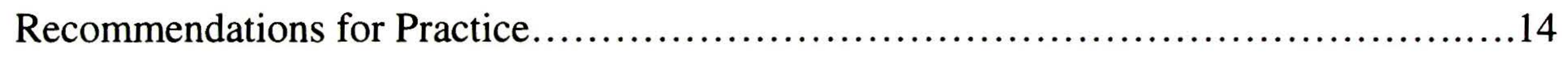

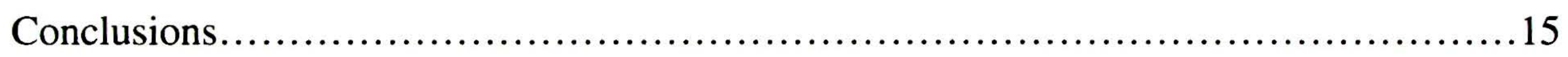

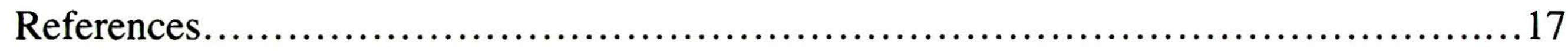

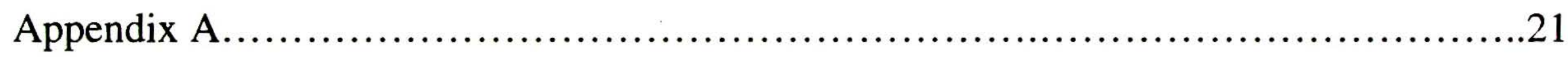




\section{CESAREAN DELIVERY AND URINARY RETENTION ASSOCIATED WITH SPINAL MORPHINE}

Cesarean delivery (CD), where the delivery of the fetus occurs through an incision in the abdomen and uterus, ${ }^{1}$ is the second most common surgical procedure in the United States (US). ${ }^{2}$ The Center for Disease Control (CDC), National Center for Health Statistics $(2007)^{3}$, reported that the CD rate in the US was $31.8 \%$ of all births. Total births in the US in 2007 were $4,317,119$, with CD's totaling $1,372,843 .{ }^{3}$ Total births in 2009 at the research site were 8,695 , including $2,837 \mathrm{CDs}$, or $32.6 \%$ of all births, consistent with national findings. ${ }^{4}$

\section{Cesarean Delivery (CD)}

Unscheduled or emergent indications for $\mathrm{CD}$ include but are not limited to: fetal intolerance to labor; lack of progress of labor; umbilical cord prolapse; breech presentation; placenta previa and placental abruption. ${ }^{5}$ Scheduled cesarean delivery indications include such factors as: elective repeat cesarean sections, cesarean delivery for malpresentation (transverse lie, breech or face presentation) of fetus, pelvic abnormalities, macrosomia (large fetus), placenta previ:t, and more recently maternal request. ${ }^{5}$ Currently, cesarean delivery on maternal request (CDMR), without medical indication, is on the rise in the US according to the American College of Obstetricians and Gynecologists (ACOG) $(2008)^{6}$ and the National Institutes of Health (NIH) (2006). ${ }^{7}$ In November of $2003, \mathrm{ACOG}^{8}$ issued a policy statement approving elective cesarean sections upon demand. They cited the principle of autonomy in taking the position that providers may ethically perform a cesarean section on a healthy woman with no medical indication as long as the physician believes that it is in the patient's best interest. The official position of the International Federation of Gynecology and Obstetrics (FIGO, 2007) ${ }^{9}$ which includes 113 member societies worldwide, is that surgical intervention without a medical rationale falls 
outside of the bounds of best professional practice. FIGO asserted that elective CD should only be performed when medically and psychologically indicated.

Common surgical complications associated with $\mathrm{CD}$ include: uterine lacerations; bladder injury; ureteral injury; bowel injury; uterine atony contributing to intra-operative or postpartum hemorrhage; wound infection; endomyometritis; fascial dehiscence; urinary tract infection; slow return of bowel function and deep vein thrombus formation. ${ }^{1}$

\section{Significance of Problem}

The Centers for Disease Control (CDC), National Center for Health Statistics (NCHS) $(2007)^{3}$ reported that the CD rate in the US was $31.8 \%$ of all births. Total births in the US in 2007 were $4,317,119$, with CDs totaling $1,372,843 .{ }^{3}$ A NCHS brief $(2010),{ }^{10}$ using preliminary data from 2007, reported an alarming 53\% increase in CDs from 1996-2007, reaching 32\%, the highest ever in the US. Cesarean rates varied considerably by state with rates as low as $25 \%$ in Alaska, Idaho, New Mexico and Utah, to as high as 35\% in Florida, Louisiana, Mississippi, New Jersey and West Virginia. The CD rate increased in all 50 states and by more than $70 \%$ in six states: Colorado, Connecticut, Florida, Nevada, Washington and Rhode Island (RI). ${ }^{10}$

Data from the NCHS report showed an 86\% increase in CDs in RI from 1996 (17.7\%) to 2007, with an estimated $32.2 \%$ of all deliveries in RI being by cesarean section. ${ }^{10}$ Second only to circumcision, $\mathrm{CD}$ is the most common surgical procedure performed in the US, contributing significantly to maternal morbidity, mortality, and escalating health care costs. ${ }^{2}$ There were 8,695 births at the study hospital in 2009 , with 2,837 (32.6\%) being CD. ${ }^{4}$ Spinal anesthesia is the most frequently utilized form of anesthesia for $\mathrm{CD}$, and it is common practice to add opioids to spinal solutions to enhance and prolong intra-operative and postoperative analgesia. This has proved to be an effective means of pain control, with minimal exposure in lactating parturients. ${ }^{11}$ A systematic review by Dahl et al. (1999) ${ }^{12}$ found that 
intrathecal morphine prolonged time to first postoperative analgesic administration and created clinically relevant reduction in postoperative pain. According to Sarvela et al. (2002) ${ }^{11}$ and Gadsen et al. (2005) ${ }^{13}$, superior pain relief, lasting approximately 24 hours, is achieved when intrathecal morphine is used at doses of $100 \mathrm{mcg}$.

Adverse effects associated with spinal anesthesia (including morphine for postoperative pain control) for CD include: pruritus, nausea and vomiting, respiratory depression, sedation, post dural puncture headache, and urinary retention. The authors reported high patient satisfaction, despite the need to treat side effects, particularly pruritus. ${ }^{11,13}$

Today, more than ever, registered nurses (RNs) are challenged to provide high quality, cost effective care to patients. The staff at the study hospital reported perceived increased occurrence of urinary retention in the $\mathrm{CD}$ patient as spinal morphine dose increased. Advanced practice registered nurses (APRNs) can assist the staff RN to implement best research evidence, combined with clinical expertise, that is utilized according to patient needs and values. Patient safety and quality of health care, as well as development of evidence based practice, are identified as global nursing priorities. ${ }^{14}$

A gap exists in research related to the relationship of spinal morphine and post $\mathrm{CD}$ urinary retention. Examining the impact of spinal morphine dose on postpartum urinary retention will allow for the development and implementation of procedure specific guidelines for removal of in-dwelling urinary catheter following CD. Re-catheterizations due to inability to void increases the postpartum patient's risk of catheter associated UTI's, length of stay, health care costs, and decreases patient satisfaction. Research in this area should help reduce maternal morbidity.

\section{Literature Review}

An extensive literature review was conducted using CINAHL, Ovid, and Pub Med. Keywords used included: cesarean delivery, urinary retention and spinal morphine. 


\section{Postoperative urinary retention (POUR)}

A systematic review by Baldini et al. (2009) ${ }^{15}$ described POUR as the inability to void in the presence of a full bladder. The reported incidence varied widely, between $5-70 \%$, likely reflecting its multifactorial etiology and lack of uniform definition. The Baldini et al. review examined the overall incidence and mechanisms of POUR associated with surgery, anesthesia, and analgesia and supported that urinary retention is common after anesthesia and surgery. Comorbidities, type of surgery, and type of anesthesia all influence the development of postoperative urinary retention (Table 1$).^{15}$

Table 1. Peri-operative risk findings for POUR risk factors

\begin{tabular}{|l|l|}
\hline Age \& Gender & Increased with age \& in men \\
\hline Drugs & $\begin{array}{l}\text { Anticholinergic agents, beta } \\
\text { blockers \& sympathomimetics }\end{array}$ \\
\hline Co-morbidities & $\begin{array}{l}\text { Neurological disease; Cerebral } \\
\text { Palsy, Multiple Sclerosis, } \\
\text { spinal lesions. Diabetes and } \\
\text { alcoholic neuropathy }\end{array}$ \\
\hline IV fluids & $\begin{array}{l}\text { Excessive use leads to over } \\
\text { distention of bladder }\end{array}$ \\
\hline Duration of surgery & $\begin{array}{l}\text { Prolonged duration increased } \\
\text { incidence }\end{array}$ \\
\hline Type of surgery & $\begin{array}{l}3.8 \% \text { in general surgery. } \\
\text { Conflicting results in } \\
\text { gynecological surgery }\end{array}$ \\
\hline Analgesia and anesthesia & $\begin{array}{l}\text { Use of long acting local } \\
\text { anesthetics and spinal opioids }\end{array}$ \\
\hline
\end{tabular}

\section{Compiled from Baldini (2009)}

Complications and adverse effects associated with POUR include: painful stimulation from an over distended bladder which can cause vomiting; bradycardia; hypotension; hypertension; and cardiac dysrhythmias. Urinary tract infection can be a direct complication of POUR as a 
consequence of bladder hypotonia and inability to completely empty the bladder, or an indirect complication of repeated bladder catheterization. ${ }^{15}$ Catheter associated urinary tract infection is the most common hospital acquired infection, and $80 \%$ of these infections are attributable to an in-dwelling catheter. ${ }^{16}$ Prevention of POUR requires the identification of patients' with perioperative risk factors. ${ }^{15}$

Baldini et al. ${ }^{15}$ suggested that intermittent catheterization is adequate for outpatient surgery and for major uncomplicated surgery with or without epidural anesthesia/analgesia. Bladder catheterization may be limited to a period of 24 hours.

\section{Postpartum urinary retention (PUR)}

Postpartum urinary retention (PUR), also known as puerperal urinary retention, is a common condition in obstetrical care which can pose significant maternal morbidity. ${ }^{17}$ The reported prevalence varies considerably from $1.7 \%$ to $17.9 \% ;^{18}$ most data were focused on PUR after vaginal delivery. ${ }^{19}$

The first study that attempted to define PUR was undertaken by Kermans et al. (1986). ${ }^{17}$ This study aimed to evaluate obstetrical trauma as a possible risk factor in PUR, determine the clinical and urodynamic profiles of this complication, and establish a simple method of treatment. Acute puerperal urinary retention was defined as the absence of spontaneous micturition within six hours of the removal of indwelling catheter in the CD patient or six hours following vaginal delivery. The study recruited 789 patients; 62 delivered by cesarean $(7.8 \%)$ and 727 delivered vaginally $(92.2 \%)$. Of the group delivered vaginally, 17 (2.3\%) had no spontaneous micturition within six hours, and in the CD group, two (3.2\%) were diagnosed with PUR, using the aforementioned definition. A total of 17 of the 789 patients $(2.2 \%$, both vaginal and CD) were diagnosed with PUR. Nulliparity (no previous pregnancy or delivery), use of epidural analgesia, and $\mathrm{CD}$ for lack of progress in the first stage- were associated factors. 
Overall incidence in this sample was found to be $2.2 \%$.

A 2002 observational prospective study, with a total of 2,866 vaginally delivered women, was conducted by Liang et al. ${ }^{20}$ to investigate the various obstetric parameters associated with PUR. The study reported that 114 of 2,866 (4\%) vaginally delivered women had PUR. They concluded that nulliparity, longer labor course, instrumental delivery, extensive vaginal and perineal lacerations, and use of epidural analgesia were contributing obstetrical factors. According to Yip et al. (2004), ${ }^{21}$ there is currently no standardized definition of PUR but a common, symptom based definition of PUR is the absence of spontaneous micturition within six hours of vaginal delivery. In the case of $\mathrm{CD}$, it is defined as no spontaneous micturition within six hours after removal of the in-dwelling urinary catheter. ${ }^{17}$

According to Liang et al. (2007), ${ }^{22}$ the precise role of CD in PUR is difficult to determine due to the effects of the operation and anesthesia. PUR can lead to bladder distention and urinary tract infection. ${ }^{22}$ Urinary retention and bladder distention are major causes of uterine atony; as the uterus is displaced by the distending bladder it loses its' ability to contract properly, increasing the risk of postpartum hemorrhage.'

\section{Postpartum Urinary Retention and CD}

Chai et al. $(2008)^{19}$ in a prospective study of 207 patients delivered by cesarean section (both scheduled and unscheduled), reported a PUR incidence of $3.38 \%$. The aim of their study was to identify the prevalence and associated risk factors of PUR after CD. PUR, for this study, was defined as a post void residual (PVR) of $150 \mathrm{ml}$ urine by transvaginal ultrasound. Foley catheters were removed 24 hours after $C D$ per hospital protocol and patients were encouraged to void six hours after removal of the foley. Their findings identified lack of progress of labor, resulting in an unscheduled $\mathrm{CD}$, as the single most important risk factor of PUR.

Liang et al. (2007) $)^{22}$ investigated the incidence of PUR in a prospective sample of 605 women 
undergoing $\mathrm{CD}$ to determine which obstetric factors contributed to the problem. Indications for CD included: previous uterine scar; abnormal presentation of fetus; placenta previa; placental abruption; cephalopelvic disproportion (CPD); multiple pregnancy; arrest of dilatation or descent: and abnormality of fetal heart rate. Data analysis showed that PUR correlated with three parameters, namely postoperative analgesia, maternal body mass index (BMI), with PUR group having a significantly lower BMI than the normal group, and CD for multiple pregnancy. Postoperative analgesia was given for 24 hours by epidural administered bolus of morphine (EBM), patient controlled epidural analgesia (PCEA) or intramuscular (IM) meperidine. They concluded that nearly one fourth of patients (24.1\%) had PUR after CD and the main contributory factor was morphine related postoperative analgesia.

Liang et al. (2010) ${ }^{23}$ compared three methods of post-operative analgesia regarding the incidence of PUR in primiparous women undergoing elective CD. In a sample of 150 postpartum women, PVR was estimated after the first micturition. PUR for this study was defined as $150 \mathrm{ml}$ residual bladder volume. The sample was divided into three groups, with 60 receiving EBM, 60 receiving PCEA, and 30 receiving IM pethidine (meperidine). The incidence of PUR in primiparous women following elective CD was $22.7 \%(n=34)$. A significantly higher incidence of PUR was found in the patients receiving EBM (33.3\%; 20 out of 60) in comparison with the two other postoperative analgesia methods, PCEA ( $15 \% ; 9$ out of 60$)$ and IM pethidine ( $16 . \% ; 5$ out of 30) $(p=0.038)$. The authors concluded that epidural anesthesia with EBM was significantly associated with post-cesarean urinary retention. Nonetheless, it was not detrimental to later urinary function.

\section{Urinary retention post $C D$ and spinal opioids}

Spinal opioids are often used for pain relief after CD. Neuraxial analgesia has proven to be an effective means of achieving post operative pain control, with minimal exposure to opioids in the 
lactating parturient. ${ }^{11}$ Regional analgesia/anesthesia provides pain relief without loss of consciousness, and is commonly used to relieve the pain of childbirth, including $\mathrm{CD}$. It involves the use of local anesthetic agents, with or without opioids, to bring about pain relief or numbness through the drug's effect on the spinal cord and nerve roots. The routes for regional pain relief include epidural block, combined spinal-epidural block, local infiltration, puedendal block and intrathecal (spinal) analgesia/anesthesia. ${ }^{.}$Spinal anesthesia involves injection of a local anesthetic, with or without opioids, into the subarachnoid space. ${ }^{1}$

Though dated, two earlier studies are of interest. Evron et al. $(1984)^{24}$ investigated 150 patients following cesarean section to evaluate the effect of epidural morphine analgesia and phenoxybenzamine on the frequency and extent of urinary complications. The sample included 40 patients receiving general anesthesia and 110 receiving epidural anesthesia. The sample was further divided into four groups: group A $(n=40)$ received general anesthesia, with mild postoperative analgesics; group B $(n=40)$ received epidural anesthesia and mild post-operative anesthetics; group C $(n=40)$ received epidural anesthesia and post operative continuous epidural morphine for pain relief; and group $\mathrm{D}(\mathrm{n}=30)$ received epidural anesthesia for $\mathrm{CD}$ and epidural morphine for post operative pain relief as well as phenoxybenzamine $10 \mathrm{mg}, 24$ hours and one hour pre-operatively, and eight and 16 hours postoperatively. The need for bladder catheterization was significantly less in group D. The authors recommended use of phenoxybenazamine in the prevention of postoperative urinary complications associated with epidural anesthesia and epidural morphine analgesia. Evron et al. (1985) ${ }^{25}$ assessed urinary function in 120 women who had undergone cesarean section with epidural anesthesia. The sample was further divided into three groups: 40 patients received epidurally administered methadone; 40 received epidurally administered morphine; and the remaining 40 received oral or intra-muscular non-opiate analgesics and sedatives. Both epidural methadone and morphine 
provided potent postoperative pain relief. Difficulty in micturition and the need for bladder catheterization were decreased in the group receiving methadone $(2.5 \%)$ in comparison with the group receiving morphine $(57.5 \%)$ or non-opiate group (12.5\%). The authors advocated for the use of epidural methadone for post operative pain relief, both in view of its analgesic potency and low incidence of urinary disturbances.

Gadsen et al. (2005) $)^{13}$ in a review of post CD analgesia, stated that a single dose of intrathecal morphine at the time of $\mathrm{CD}$ can provide excellent analgesia of prolonged duration. A meta-analysis by Dahl et al. (1999) ${ }^{12}$ on post CD analgesia described adverse effects of intrathecal morphine as pruritus, nausea and vomiting, early or delayed respiratory depression, and urinary retention. According to this meta-analysis the adverse effects of neuraxial opioids are well described, and although not infrequent, can be classified primarily as "nuisance" side effects that are easily treated, rather than those that are dangerous or life-threatening. They concluded that the main finding of this systematic review was that intrathecal (spinal) morphine prolonged time to first post-operative analgesic administration and created a clinically relevant reduction in post-operative pain and analgesic consumption.

A gap exists in the nursing literature related to urinary retention in the post $C D$ patient who has received spinal morphine for post operative pain control.

\section{Purpose}

The purpose of the study was to examine the relationship between post CD urinary retention and dose of spinal morphine

\section{Framework and Conceptual Model}

The framework used to guide this research was the American Society of PeriAnesthesia Nurses (ASPAN) Evidence-Based Practice (EBP) Conceptual Model (2006) (Figure 1). ${ }^{26}$ ASPAN's EBP Model exists to support perianesthesia nurses in the global nursing community within three core 
domains of the nursing specialty organization: clinical practice, education and research. The goal of this model is to guide nursing staff in using evidence based data to identify and introduce more efficient and effective ways to resolve problems in the perianesthesia setting. Evidence based practice in this model consists of five stages: explore the problem, collect the information, propose change, implement the plan and evaluate the outcome.

The ASPAN model was used to explore the relationship between spinal morphine dose and post CD urinary retention. Data was collected related to the occurrence of post CD re-catheterizations. Following 2008-2010 standards of perianesthesia nursing practice, research findings should provide sufficient evidence to guide decision making in the nurse's clinical, educational or management role.

\section{Figure 1.}

ASPAN's Evidence Based Practice Model

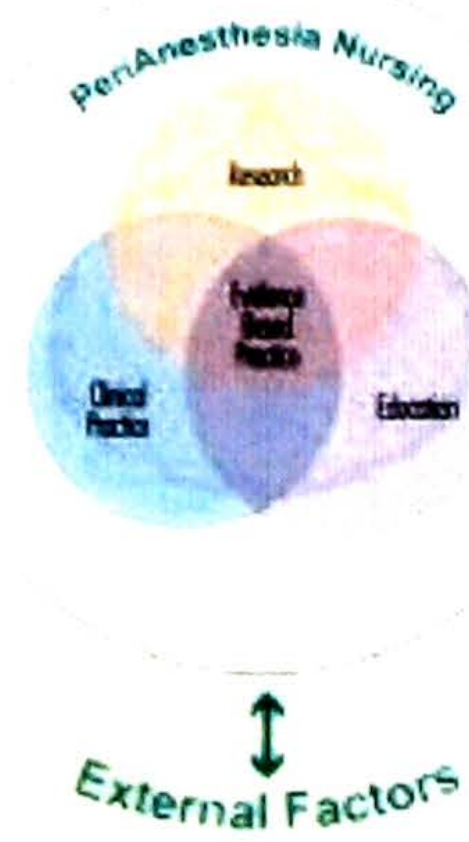

ASPAN (C) All rights reserved, April 2006

\section{Methods}

The aim of the study was to examine the relationship between spinal morphine dose and urinary retention in the elective $\mathrm{CD}$ population. 


\section{Research Design}

A retrospective quasi-experimental three group design included the following comparison groups: subjects receiving $100 \mathrm{mcg}$ spinal morphine $(n=50), 150 \mathrm{mcg}$ spinal morphine $(n=50)$, and subjects receiving $200 \mathrm{mcg}$ spinal morphine $(\mathrm{n}=50)$. Hypothesis: There is a positive relationship between urinary retention post $\mathrm{CD}$ and dose of spinal morphine. Variables: independent variable was spinal morphine dose; dependent variable was urinary retention. Key extraneous variables included: body mass index (BMI); age; and primary vs. repeat CDs.

\section{Sample}

A convenience sample of 150 women up to and including 39 years of age, who had undergone elective $\mathrm{CD}$ at term (37 weeks or greater), including both primary and repeat $\mathrm{CD}$.

\section{Exclusion Criteria}

Exclusions were based on a review of the literature and clinical practice experience and included: age $>39$ years; emergent and non-elective CDs; multiple gestations; preterm CDs; CDs not receiving spinal morphine for post-op pain relief; concurrent neurological diseases such as stroke, poliomyelitis, cerebral palsy, multiple sclerosis, spinal lesions, diabetic and alcoholic neuropathy. ${ }^{15}$

\section{Setting}

The study was conducted in a 167 bed academic women's hospital, with 122 obstetrical beds, the seventh largest obstetrical hospital in the nation. In 2009 there were 8,695 deliveries, which included 2,837 CDs. ${ }^{4}$ 


\section{Procedures}

Permission was obtained from the research hospital and college Institutional Review Boards (IRBs). Verbal approval from the Chief Department of Anesthesia and Senior Vice President of Patient Care Services was also secured. Following approval, data were collected from October 2010 through April 2011 until the required sample size was met. The retrospective sample included CD's that occurred prior to September 2010. Medical records were randomly retrieved by health information management (HIM) staff and placed on a shelf for the PI to review. On a daily basis, the PI went to the HIM office and examined the paper records for inclusion/exclusion criteria. Records meeting inclusion criteria were then further reviewed via an electronic medical record (EMR). This occurred because the site had a combination paper and electronic medical record. All records were returned to HIM staff once data was extracted. A researcher designed data collection tool (Appendix A) was developed to obtain such information as: date of surgery; primary versus repeat cesarean delivery; weeks of gestation; morphine dose; bladder assessment; repeat catheterization; body mass index; maternal age and urinary retention. After completion, the PI- developed data extraction documents were then stored in a locked file cabinet to which only the researcher had access.

\section{Data Analysis}

Descriptive statistic techniques were used to summarize findings obtained from the data collection tool. Group frequency distributions were graphed to show morphine dose; weeks of gestation; repeat catheterization; age; BMI; R (repeat) CD vs. P (primary) CD. Differences between the groups related to urinary retention were examined. 


\section{Results}

A total of 150 records were reviewed, 50 from each group. Table 1 illustrates the ages of the participants by decade.

Table 1. Age distribution of study participants

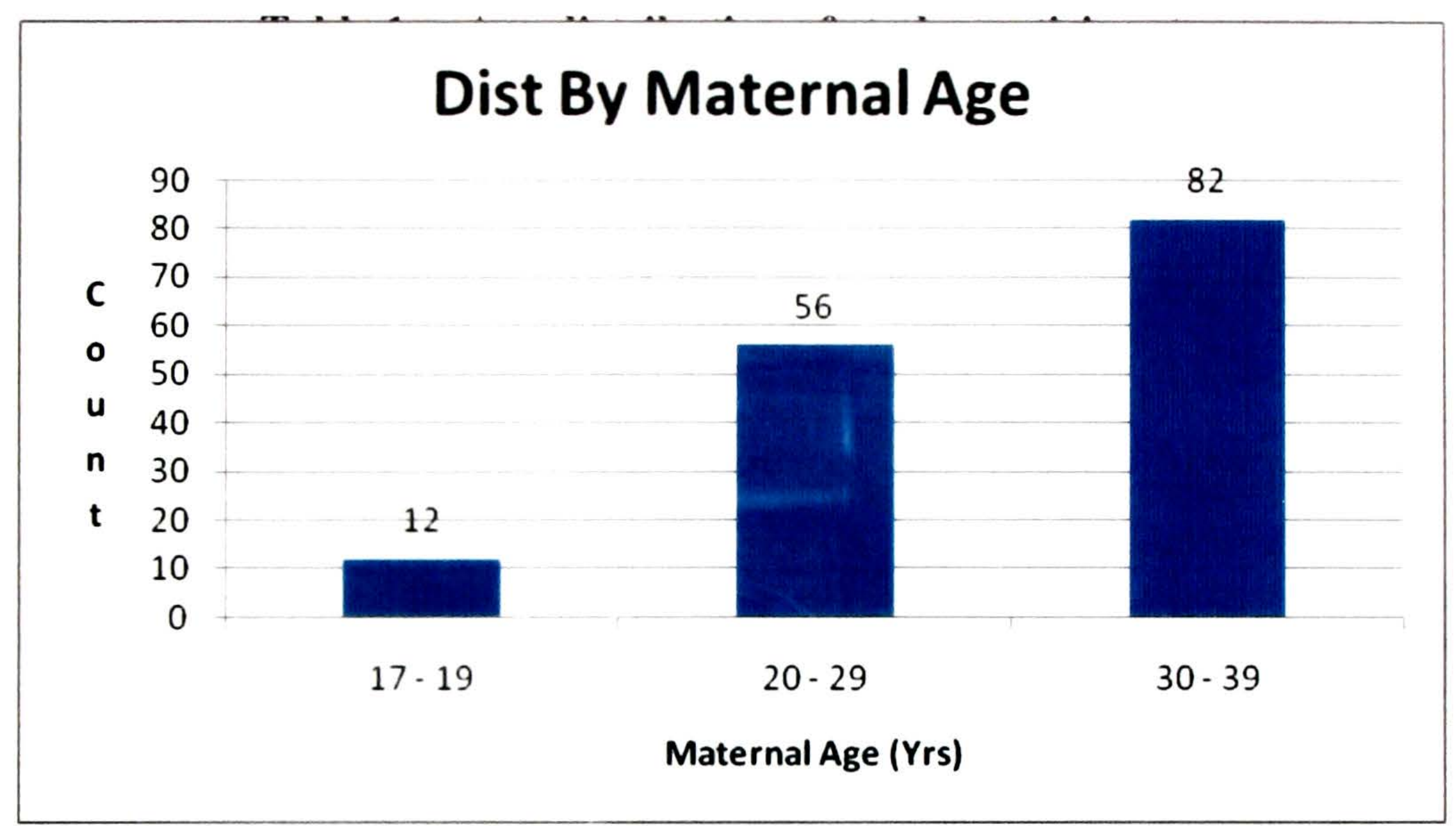

As illustrated, greater than half $(n=82 ; 55 \%)$ of the paiticipants were in the 30-39 age gruup.

Table 2 illustrates morphine dose by type of CD.

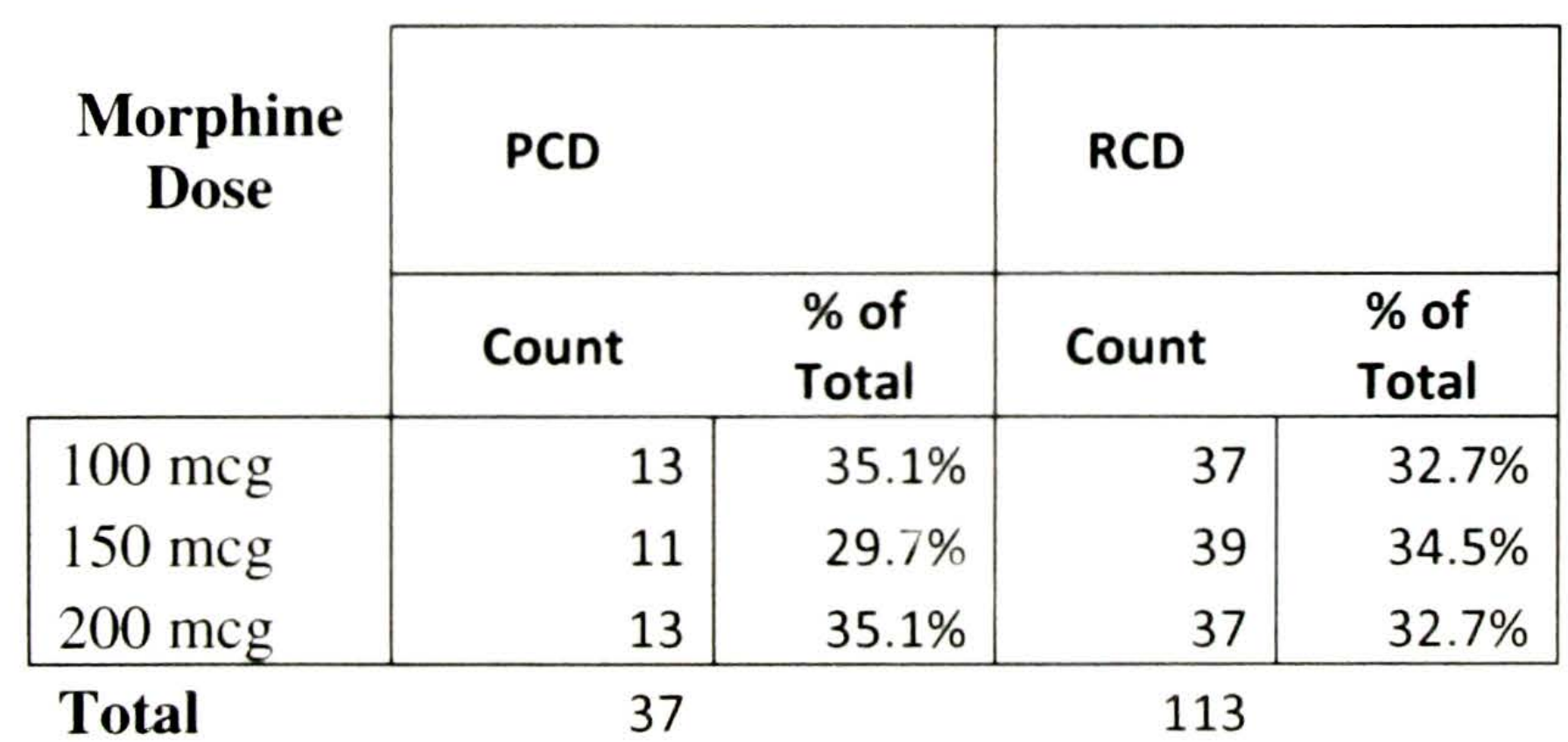


As can be seen, there were less primary than repeat $C D^{\circ}$ s. but number of participants within primary and repeat groups were about equal. It is interesting to note that each of the three morphine doses $(100,150,200 \mathrm{mcg})$ in the two groups (primary or repeat). were about equally represented, each being about one third of the total amount given.

Of the total sample, one subject who had received $150 \mathrm{mcg}$ of spinal morphine was noted to have PUR as evidenced by repeated urinary catheterization. Since only one subject was documented with PUR, no further examination for differences between the groups was conducted.

\section{Discussion of Findings}

The purpose of the study was to compare the occurrence of post elective CD urinary retention and dose of spinal morphine. Findings from this study did not support the proposed research hypothesis that a positive relationship existed between spinal morphine dose and post elective CD urinary retention. The main finding was that spinal morphine in doses of $100 \mathrm{mcg}, 150$ $\mathrm{mcg}$, and $200 \mathrm{mcg}$ can be used to provide effective postoperative pain management without increasing rate of urinary retention.

\section{Limitations}

The study was limited to patients undergoing elective primary or repeat $C D$, so findings are not generalizable to the emergent or non-elective $\mathrm{CD}$ population who receive spinal morphine. Given that this was a retrospective design, the researcher was unable to determine whether re-catheterization might have occurred without documentation in the medical record. Data related to pre-pregnancy BMI were not available in the record. Since limited demographic information was gathered, other factors, such as ethnicity, might have impacted results. 


\section{Recommendations for Practice}

The results of this study illustrated that increased PUR did not exist in this elective CD population. Increased occurrence in the emergent $\mathrm{CD}$ population, and $\mathrm{CD}$ population having epidural bolus of morphine for postoperative pain relief, has been well documented in the literature. Present hospital policy for removal of urinary catheters in the post CD population is effective. Further research examining the relationship of spinal morphine dose and urinary retention in the emergent and non-elective $\mathrm{CD}$ patient is recommended. Further study of other potential influencing variables, including selected demographic variables and ethnically diverse samples, is indicated. Collaboration between staff nurses, nursing management, and the CNS should be supported and encouraged to prevent existing "research to practice" gaps. ${ }^{26}$

\section{Conclusions}

$\mathrm{CD}$ is the second most common surgical procedure in the US. ${ }^{3}$ The Association of Women's Health, Obstetric, and Neonatal Nurses' guidelines for peri-operative care of the pregnant woman state: "The safety of women undergoing surgical or obstetric procedures depends significantly on the competence, attentiveness, and experience of the peri-anesthesia nurse" (p.28). ${ }^{27}$ Post-partum nursing staff are encouraged to identify factors that influence patient outcomes and work with the Clinical Nurse Specialist (CNS ) to conduct and translate research and bring best practice recommendations to the bedside. The basic construct of ASPAN's EBP Model exists to support peri-anesthesia nurses in the global nursing community within three core domains of the nursing specialty organization: clinical practice, education and research. ${ }^{26}$ Improved quality of care and greater patient satisfaction result when barriers to EBP are removed. The CNS is pivotal in encouraging staff nurses to ask and answer questions related to patient care and outcomes. He/she can assist staff in identifying problems, conducting performance improvement activities, reviewing the literature for best practices, educating 
interdisciplinary staff, and acting as a translator and facilitator of nursing research. ${ }^{28}$ The CNS is uniquely trained to work within and across the patient, nursing and systems/ organizational sphere, and plays a major role in impacting policy at the institutional and national level.

Lobbying to impact CD rates at the local, state, and national level is a critical advanced practice role in improving patient outcomes. 


\section{References}

1. Scott-Ricci S. Essentials of Maternity, Newborn, and Women's Health Nursing. Philadelphia, PA. Lippincott Williams and Wilkins; 2007

2. Hamilton BE, Martin JA, Ventura SJ. Births: Preliminary data for 2005, National Vital Statistics Reports, 2006; 53(11), 1-18.

3. Centers for Disease Control, National Center for Health Statistics (2009). Retrieved July 17, 2010, from http://www.cdc.gov/media/pressrel/2009/r090318.htm

4. Quality Management Department, Women \& Infants Hospital (2009)

5. Collard TD, Diallo H, Habinsky A, Hentschell C, Vezeau TM. Elective cesarean section. Why women choose it and what nurses need to know. Nursing for Women's Health December 2008 January 2009; 481-488.

6. Association of Obstetrics and Gynecology. (2008) Surgery and patient choice. Retrieved July 2010 from http://www.acog.org/from_home/publications/ethics/co395.pdf

7. National Institute of Health. (2006). NIH State-of-the-Science conference: Cesarean delivery on maternal request. Retrieved July 15, 2010, from http://consensus.nih.gov/2006/2006CesareanSOS027Statementhtml.htm

8. American College of Obstetricians and Gynecologists. (2008). Surgery and patient choice. Retrieved July 15, 2010, from http://www.acog.org/from_home/publications/ethics/co395.pdf

9. International Federation of Gynecologists and Obstetricians. (2007). FIGO statement on caesarean section. Retrieved July 18, 2010, from http://www.figo.org/Caesarean.asp

10. Centers for Disease Control, National Center for Health Statistics, Data Brief No. 35. (2010). Recent trends in Cesarean Delivery in the United States. Retrieved July 17, 2010, from http://www.cdc.gov/media/pressrel/2009/r090318.htm 
11. Sarvela J, Halonen P. Soikkeli A, Korttila K. A double-blinded, randomized comparison of intrathecal and epidural morphine for elective cesarean delivery. Anesth Anal 2002; p. 436.

12. Dahl JB, Jeppesen IS, Jorgensen H. Wetterslev J, Moiniche S. Intraoperative and postoperative analgesic efficacy and adverse effects of intrathecal opioids in patients undergoing cesarean section with spinal anesthesia. A qualitative and quantitative systematic review of randomized controlled trials. Anesthesiology 1999; 91:1919-27.

13. Gadsen J, Hart S. Santos AC. Post-cesarean delivery analgesia. Anesth Anal 2005: 101: S62-S69.

14. Sigma Theta Tau International, Position Paper (2005). Resource Paper on Global Health and Nursing Research Priorities. p. 2

15. Baldini G, Bagry H. Aprikian A. Carli F, Phil M. Postoperative urinary retention. Anesthetic and perioperative considerations. Anesthesiology, 2009; 110: 1139-1157.

16. Saint S, Chenowith CE. Biofilms and catheter-associated urinary tract infections. Infect Dis Clin North Am2003: 17: 411-432.

17. Kermans G, Wyndaele JJ. Thiery M, De Sy W. Puerperal urinary retention. Acta Urologica Belgica 1986;54:376-385.

18. Saultz JW. Toffler WL, Shackles JY. Postpartum urinary retention. JABFP Sept.Oct.1991: Vol.4 No.5 341-4.

19. Chai AHL. Wong T, Mak HLJ, Cheon C. Yip SK, Wong ASM. Prevalence and associated risk factors of retention of urine after caesarean section. Int Urogynecolo J 2008; 19:537-542. 
20. Liang CC, Chang SD, Tseng LH, Hsieh CC, Chung CL, Cheng PJ. Postpartum urinary retention: assessment of contributing factors and long-term clinical impact. Aust $\mathrm{N} \mathrm{Z} \mathrm{J}$ Obststet Gynaecol 2002; 42:365-368

21. Yip SK, Brieger G, Hin LY, Chung T. Urinary retention in the post-partum period, the relationship between obstetric factors and the post-partum post-void residual bladder volume. Acta Obstet Gynec Scand 1997; 76: 667-672.

22. Liang CC, Chang SD, Chang YL, Chen SH, Chueh HY, Cheng PJ. Postpartum urinary retention after cesarean delivery. International Journal of Gynecology and Obstetrics 2007; 99:229-232.

23. Liang CC, Chang SD, Wong, SY, Chang YL, and Cheng PJ. Effects of postoperative analgesia on postpartum urinary retention in women undergoing cesarean delivery. Journal of Obstetrics and Gynecology Research 2010; 36:991-995.

24. Evron S, Samueloff A, Sadovsky E, Berger M, Magora F. The effect of phenyoxybenzamine on postoperative urinary complications during extradural morphine analgesia. Eur J Anaesthesiol 1984; 1: 45-54.

25. Evron S, Samueloff A, Simon A, Drenger B, Magora F. Urinary function during epidural analgesia with methadone and morphine in post-cesarean section patients. Pain 1985; 23: $135-44$.

26. Mamaril ME, Ross JM, Krenzischek D, O’Brien D, Wilson L, Clark M, Clifford T, Hooper V. The ASPAN's EBP Conceptual Model: Framework for Perianesthesia Practice and Research. Journal of PeriAnesthesia Nursing, 2006; 21: 157-167.

27. Association of Women's Health, Obstetric, and Neonatal Nurses. Guidelines for perioperative and perianesthesia/anesthesia care of the pregnant woman. Washington, DC: AWOHNN; (2001) p. 28. 
28. Artz, BA, March, KS, Grim, RD. National Association of Clinical Nurse Specialist

National Conference Abstracts (2011). Lippincott Williams and Wilkins, p. 75. 
Appendix A

Researcher developed Data Collection Grid

\begin{tabular}{|c|c|c|c|c|c|c|c|c|c|}
\hline $\begin{array}{l}\text { Date of } \\
\text { Surgery }\end{array}$ & PCD & $\mathrm{RCD}$ & $\begin{array}{l}\text { Weeks of } \\
\text { Gestation }\end{array}$ & $\begin{array}{l}\text { Morphine } \\
\text { Dose }\end{array}$ & $\begin{array}{l}\text { Bladdesr } \\
\text { assessment }\end{array}$ & $\begin{array}{l}\text { Urinary } \\
\text { retention }\end{array}$ & $\begin{array}{l}\text { Repeat } \\
\text { catheterization }\end{array}$ & BMI & $\begin{array}{l}\text { Maternal } \\
\text { age }\end{array}$ \\
\hline & & & & & & & & & \\
\hline & & & & & & & & & \\
\hline & & & & & & & & & \\
\hline & & & & & & & & & \\
\hline & & & & & & & & & \\
\hline & & & & & & & & & \\
\hline
\end{tabular}

